\title{
Uma narrativa anti-orientalista: os quadrinhos contra-hegemônicos de
}

\author{
Joe Sacco \\ An Anti-Orientalist Narrative: Joe Sacco's Counter-Hegemonic Comics \\ Una narrativa anti-orientalista: los cómics contrahegemónicos de Joe Sacco
}

Débora Pinese Frias ${ }^{1}$

\begin{abstract}
Resumo: A reportagem em quadrinhos Palestina (2011) é um relevante trabalho de aproximação a questão palestina representada em suas páginas. Configurou também uma importante quebra com as produções culturais e jornalísticas estadunidenses da década de 1990, temporalidade de sua elaboração e publicação. Seu autor, Joe Sacco, um nome reconhecido pelas suas histórias em quadrinhos e pela junção dessa linguagem com os métodos clássicos do jornalismo, conseguiu neste trabalho se opor ao orientalismo hegemônico da opinião pública estadunidense. O presente artigo, portanto, se propõe a refletir sobre a obra como uma narrativa contra-hegemônica, que permite uma análise do contexto palestino a partir do conceito de limpeza étnica, de Ilan Pappé. Essa interpretação provém de resultados parciais da monografia defendida por mim ao início do ano de 2021.
\end{abstract}

Palavras-chave: Palestina; Reportagem em quadrinhos; Contra-hegemonia; Limpeza Étnica

Abstract: The graphic novel Palestine (2011) is a relevant work on an approach to the Palestinian issue, represented in its pages. It also configurated on an important break with the cultural and journalistic productions in the United States of America in the 1990s, the temporality of its elaboration and publication. Its author, Joe Sacco, a name recognized for his graphic novels and for the combination of this language with the classic methods of journalism, managed in this work to oppose the hegemonic Orientalism of public opinion in the US. The present article, therefore, proposes to reflect the work as a counter-hegemonic narrative, that allows an analysis of the Palestinian context from the concept of ethnic cleansing, by Ilan Pappé. This interpretation comes from partial results of the monographic work defended by me at the beginning of the year 2021 .

Key Words: Palestine; Graphic novel; Counter-hegemony; Ethnic Cleansing.

Resumen: El cómic Palestina (2011) es una obra relevante para abordar la cuestión palestina representada en sus páginas. También representó una ruptura importante con las producciones culturales y periodísticas estadounidenses de los años noventa, la temporalidad de su elaboración y publicación. Su autor, Joe Sacco, nombre reconocido por sus cómics y por la combinación de este lenguaje con los métodos clásicos del periodismo, logró en este trabajo oponerse al orientalismo hegemónico de la opinión pública estadounidense. Este artículo, por tanto, propone reflexionar sobre el trabajo como una narrativa contrahegemónica, que permite un análisis del contexto palestino desde el concepto de limpieza étnica, de Ilan Pappé. Esta interpretación proviene de resultados parciales de la monografía que defendí a principios del año 2021 .

\footnotetext{
${ }^{1}$ Atualmente Mestranda pelo Programa de Pós-graduação em História da Universidade Federal de São Paulo (PPGH/UNIFESP) e licenciada em História pela Universidade Federal de São Paulo (UNIFESP), campus Guarulhos. Membro do Laboratório de Estudos Orientais e Asiáticos (LEOA/UNIFESP) e da comissão organizadora e idealizadora da I Jornada Afroasiática de História (UNIFESP).
} 
Palabras Clave: Palestina; Cómics; Contrahegemonía; Limpieza étnica.

\section{Introdução}

As histórias em quadrinhos configuram uma linguagem que combina recursos visuais e verbais para realizar a comunicação da narrativa pretendida por seus autores. Foram, e ainda podem ser, uma importante forma de construção e disseminação de histórias voltadas sobretudo, ao público infantil. No entanto, a partir dos anos 1960, os movimentos sociais candentes de contracultura e as novas compreensões sobre as possibilidades que este tipo de linguagem proporciona, impactaram no cenário dessas produções culturais, trazendo mudanças tanto em âmbito narrativo, como na variedade dos públicos-alvo a serem atingidos.

De acordo com Antônio Aristides Corrêa Dutra (2003),

Com os anos 1960 e 70 da contracultura, dos hippies e do pop, os quadrinhos foram virados de pernas para o ar. Alguns autores radicalizaram o caráter fantasioso das histórias em quadrinhos, com uma ficção científica absolutamente lisérgica enquanto outros preferiram subvertê-la com uma espécie de choque de realidade ${ }^{2}$.

Nesse momento, portanto, as narrativas em quadrinhos inauguraram um novo nicho, com produções que subverteram os padrões anteriores esperados em histórias voltadas às crianças, que buscavam necessariamente um caráter ficcional e lúdico. Além disso, as décadas posteriores, de 1970 e 1980, foram marcadas por uma complexificação dos enredos, apresentando também temáticas mais sensíveis, o que levou a um novo grupo de consumidores mais maduros. As biografias também se apresentaram como tramas para as HQs, sobretudo a partir dos anos de 1980, em que os autores e autoras desfrutavam de uma maior liberdade criativa para suas histórias ${ }^{3}$.

Herdeiro desses movimentos iniciados na segunda metade do século XX e que impactaram nas produções de histórias em quadrinhos a partir de então, o quadrinista Joe Sacco pode aproveitar dessas mudanças no campo para pavimentar seu próprio caminho com suas inovações. Nascido em 1960 na Ilha de Malta, se mudou junto à sua família com destino à Austrália e no início de sua adolescência, aos 12 anos, emigrou para os Estados Unidos. Em 1981, se formou em jornalismo pela Universidade de Oregon, no entanto, parafraseando o próprio autor,

\footnotetext{
2 Antônio Aristides Corrêa Dutra. "Quadrinhos de não-ficção”. In: INTERCOM- Sociedade Brasileira de Estudos Interdisciplinares da Comunicação XXVI Congresso Brasileiro de Ciências da Comunicação, 2003, Belo Horizonte (MG), (não paginado).

${ }^{3}$ Ana Paula Silva Oliveira; Mateus Yuri Passos. "Joe Sacco: jornalismo literário em quadrinhos”. (VI ENCONTRO DOS NÚCLEOS DE PESQUISA DA INTERCOM, Campinas, 2006) p. 2-3.
} 
por não conseguir se satisfazer com trabalhos jornalísticos, após a sua graduação se dedicou aos quadrinhos, os quais considerou a "paixão de sua vida"4

A fonte utilizada como base para o presente artigo é a história em quadrinhos Palestina, escrita por Joe Sacco e publicada no país pela Conrad Editora do Brasil, no ano de 2011. O seu conteúdo foi organizado em uma edição especial de 328 páginas e tradução de Cris Siqueira. O volume é dividido em nove capítulos, além de contar com um prefácio do crítico literário palestino Edward W. Said; um prefácio exclusivo da edição brasileira escrito pelo jornalista José Arbex Jr.; e um prefácio do autor da obra. Este material complementar apresenta relevantes informações sobre Joe Sacco, em especial, naquele escrito pelo próprio jornalista maltês, pois disponibiliza aos leitores, trechos de suas primeiras anotações sobre a Palestina, que serviram de conteúdo basilar para a posterior escrita e criação de seus quadrinhos.

Originalmente, a história que analisamos foi publicada entre os anos de 1993 e 1995, nos Estados Unidos da América, pela editora underground Fantagraphics Books. Os nove capítulos pertencentes na edição especial da Conrad Editora do Brasil são frutos da junção dos nove volumes originais, veiculados de modo fragmentado ao longo desses dois anos ${ }^{5}$. As primeiras traduções para o português brasileiro foram publicadas também pela Conrad Editora do Brasil, e inicialmente foram divididas em dois volumes: Palestina: Uma Nação Ocupada (2000) e Palestina: Na Faixa de Gaza (2003); contando com 5 e 4 capítulos em cada uma respectivamente.

Ao abordá-la como fonte histórica, vale ressaltar aqui uma característica peculiar da obra, que é um traço marcante nas produções de Joe Sacco: o gênero reportagem em quadrinhos. À primeira impressão, uma categoria que pode aparentar paradoxal, em Palestina aparece como um exemplo de narrativa que junta aspectos específicos de um trabalho jornalístico, porém, o faz nos moldes da linguagem de história em quadrinhos.

A possibilidade de junção de duas formas narrativas que em um primeiro momento podem parecer distantes, foi possível porque o autor fez uso da metodologia apreendida em sua formação em jornalismo, enquanto não abriu mão de suas liberdades e criatividade para representar as informações coletadas. O trabalho elaborado por Joe Sacco contou com uma recolha de conteúdo a partir de entrevistas e depoimentos; fontes visuais; trabalho de campo etc.. Todo esse compilado de informações foi possível devido à viagem de dois meses do jornalista para

\footnotetext{
${ }^{4}$ Joe Sacco. "Algumas reflexões sobre Palestina". In: cial. São Paulo: Conrad Editora do Brasil, 2011) p. XVII.

${ }^{5}$ As capas dos nove volumes originais podem ser conferidas no prefácio de Joe Sacco presente na Edição Especial da Conrad Editora do Brasil. In: SACCO, Joe. Palestina. Tradução de Cris Siqueira. (Edição Especial. São Paulo: Conrad Editora do Brasil, 2011), p. XXXVIII - XXXIX.
} 
os territórios ocupados da Palestina, entre os anos de 1991 e 1992. O resultado que buscava, portanto, era de uma narrativa baseada em fatos reais.

Sua motivação para tal trabalho decorreu de um despertar pessoal para se contrapor frente ao discurso consolidado no jornalismo estadunidense sobre a ocupação israelense em terras palestinas. Isso se deu sobretudo após o ataque de Israel a Beirute, a consequente invasão do Líbano e os ataques aos campos de refugiados de Sabra e Shatila no início da década de $1980^{6}$. Após estes eventos, Sacco relatou em seu prefácio que:

\begin{abstract}
Além do nebuloso dever de compadecer-me com o sofrimento de um povo distante, a situação me incomodava em outros dois níveis: como americano pagador de impostos, cujo dinheiro - meu dinheiro - estava sendo empregado para perpetuar uma ocupação, e como graduado em jornalismo pela Universidade do Oregon, pois estava abismado com a fraca - terrível seria mais adequado - cobertura que os jornalistas norte-americanos estavam dando à questão ${ }^{7}$.
\end{abstract}

Lidando com a tarefa ambiciosa de trazer uma nova perspectiva ao público estadunidense, sobre um conflito pelo qual a maioria dos grandes veículos midiáticos já tinham se posicionado em defesa ao Estado de Israel - em maior ou menor grau de explicitude -, Joe Sacco fez a sua viagem à Palestina. Por conseguinte, em seu trabalho de pesquisa jornalística in loco entre os anos de 1991 e 1992, pôde reunir relatos, anotações, fotografias e esboços que produziu em sua viagem para a Palestina durante dois meses. O jornalista considerou que seu trabalho se baseou, em grande parte, em “entrevistas formais, em clássico estilo jornalístico”, a partir do diálogo com os entrevistados e entrevistadas, questionando-os sobre suas experiências e anotando as informações a ele concedidas em um caderno ${ }^{8}$.

Os recursos imagéticos também tiveram importância nesse trabalho de recolha e confecção de materiais pelos quais Joe Sacco baseou o seu posterior trabalho. Em relação às fotografias, o autor alega terem sido apenas "poucas dezenas de fotos" tiradas por ele, em combinação com a busca por trabalhos foto-jornalísticos, ou livros já publicados, que puderam servir como referências visuais auxiliares. Suas anotações também tiverem um papel importante na construção imagética da história em quadrinhos, devido ao detalhamento em palavras das experiências que testemunhou ${ }^{9}$. Um terceiro artifício utilizado, foram esboços feitos pelos entrevistados a fim de ilustrar o local ao qual se referiam, como na entrevista de Joe Sacco com exdetentos de Al-Ansar, que esboçaram o complexo prisional a fim que o autor pudesse inserir acontecimentos relatados sobre o local em seus quadrinhos ${ }^{10}$.

\footnotetext{
${ }^{6}$ Joe Sacco. op cit. 2011. p. XVI.

${ }^{7}$ Ibidem.

${ }^{8}$ Idem, p. XVIII.

${ }^{9}$ Idem, p. XXIX

${ }^{10}$ Idem, p. XXX.
} 
Após esse panorama sobre os métodos jornalísticos de recolha de informações empregados pelo autor, se faz necessário entender o que possibilitou a escolha particular da representação do contexto palestino por meio da linguagem quadrinística. Como já pontuado, os quadrinhos são predominantemente compostos por elementos visuais e na grande maioria das vezes, retratavam narrativas ficcionais e comerciais. No entanto, seria errôneo considerar que as histórias em quadrinhos estão apartadas da materialidade. Pelo contrário, são produtos histórico-culturais, inseridos em seus contextos de produção e que carregam mensagens, ideologias e valores, de forma subliminar ou explícita.

De acordo com Patrícia Rangel (2014), as histórias em quadrinhos podem ser um importante veículo de disseminação e afirmação de valores específicos de uma sociedade, principalmente quando voltadas ao público infanto-juvenil. Isso porque, de uma forma pedagógica e disciplinadora, pode apresentar aos leitores quais padrões, normas e convenções devem ser assimilados e propagados. A autora aponta, que as personagens "Tintim, Mickey, Tio Patinhas, Superman e tantos outros são por excelência arquétipos da supremacia europeia e do sucesso capitalista." ${ }^{11}$. Essas personagens, portanto, mais do que serem criadas para o entretenimento infanto-juvenil, foram utilizadas para a consolidação de um discurso de valorização das sociedades ocidentais e seus modelos econômicos e políticos.

O interesse em estudar Palestina, de Joe Sacco, portanto, está na contraposição do autor em relação a esse tipo de representação. A investigação sobre as particularidades, o posicionamento do autor a partir da sua obra, e a compreensão do contexto de sua produção, pode nos trazer resultados para a relevância dos discursos contra-hegemônicos e anti-orientalistas nas temáticas sobre a Palestina. Nos próximos tópicos objetivou-se explorar como o autor concretizou a sua produção, tendo como ponto de partida os questionamentos referentes a cobertura jornalística estadunidense e a realidade do povo palestino sob ocupação israelense.

\section{Palestina e a quebra com o orientalismo dos EUA}

Para iniciar a análise da reportagem em quadrinhos, há a necessidade de atestar a importância das produções culturais como fontes da pesquisa acadêmica. Dessa forma, recupero o trabalho de Maria Elisa Cevasco, As dez lições sobre estudos culturais (2003), em que a autora

\footnotetext{
${ }^{11}$ P. Rangel. "Desenhando o conflito Israel-Palestina: narrativas e representações em HQs". Malala, n. 3, 2014. p. 100.
} 
atribui aos autores Raymond Williams, Edward Palmer Thompson e Richard Hoggart, a centralidade na fundação acadêmica dessa área de estudos, durante a década de $1950^{12}$. Em decorrência dessas abordagens, apresenta-se a relevância de uma produção historiográfica que parta da inter-relação entre fenômenos culturais e socioeconômicos, para assim compreender o contexto estudado e contribuir a favor das devidas mudanças sociais.

Segundo Cesvasco (2003),

A diferença fundamental que a contribuição de Williams traz ao debate é a percepção materialista de cultura: os bens culturais são resultado de meios também eles materiais de produção [...], que concretizam relações sociais complexas envolvendo instituições, convenções e formas ${ }^{13}$.

No caso estudado neste artigo, portanto, a reportagem em quadrinhos Palestina deve ser entendida a partir de uma percepção materialista de cultura. Tendo isso em vista, devemos analisar a obra em relação ao contexto de sua produção, pensando em duas chaves. A primeira, a partir das produções de histórias anteriores e contemporâneas a de Joe Sacco, que podem ter o influenciado em suas escolhas narrativas e estéticas, como visto na Introdução. A segunda, em relação a como o autor decidiu por quebrar com um hegemonismo discursivo e ideológico presente no jornalismo estadunidense na década de 1990 e, em resposta, apresentar uma defesa aos palestinos ${ }^{14}$.

Com o objetivo de se conceituar hegemonia, para então atribuirmos adequadamente o caráter contra-hegemônico na obra de Joe Sacco, os estudos de Antonio Gramsci sobre o conceito são fundamentais. Hegemonia, para Gramsci, decorre da concepção da existência de um ponto de contato entre sociedade civil e sociedade política, as quais lutam pelo monopólio dos órgãos de opinião pública, com o objetivo de que apenas uma dessas forças tenha a possibilidade de modelar a opinião nacional. Esse domínio da opinião pública, portanto, busca a desagregação das discordâncias, de forma a apagá-las e assim intentar a sua homogeneização ${ }^{15}$.

O monopólio da opinião pública dos Estados Unidos está intrinsecamente ligado com concepções e estereótipos construídos a partir das categorias de Oriente e Ocidente. Sobre esses dois conceitos, como apresentado por Edward W. Said (2016),

Tanto quanto o próprio Ocidente, o Oriente é uma ideia que tem uma história e uma tradição de pensamento, um imaginário e um vocabulário que lhe deram realidade e

\footnotetext{
12 M. E. Cevasco. Dez lições sobre estudos culturais. (1.ed. São Paulo: Boitempo, 2003) p. 12-13.

${ }^{13}$ Idem, p. 23.

14 Em seu prefácio, Joe Sacco atribui sua "reeducação" sobre a questão palestina "aos livros Blaming the Victims, organizado por Christopher Hitchens e Edward Said, The Question of Palestine, também de Said, e The Fateful Triangle, de Noam Chomsky." In: SACCO, Joe. op cit., 2011. p. XVII.

${ }^{15}$ Antonio Gramsci. Cadernos do cárcere: volume 3: Maquiavel, notas sobre o estado e a política. (3. ed. Rio de Janeiro: Civilização Brasileira, 2007. v. 3) p. 265.
} 
presença no e para o Ocidente. As duas entidades geográficas, portanto, sustentam e, em certa medida, refletem uma à outra ${ }^{16}$.

A construção do Oriente pelo Ocidente, portanto, implica na criação da própria identidade ocidental a partir da ideia relacional de alteridade e diferença com aquele que identifica como extremo oposto. Devemos compreender também que estas categorias não são concepções feitas de forma idônea e sem motivações políticas, econômicas e sociais. Said apresenta em Orientalismo (2016) justamente como a partir do projeto de dominação francesa sobre o Egito, empreendido por Napoleão Bonaparte ao final do século XVIII, uma série de encontros ocidentais com o Oriente se sucederam. Nesses encontros, os conhecimentos produzidos pelo campo intelectual orientalista foram essenciais, como forma de respaldar as intenções imperialistas das diferentes potências ocidentais, conforme o respectivo momento histórico ${ }^{17}$.

Isso porque, apesar da existência de um conjunto de ideias e saberes que consolida o discurso orientalista ser uma constante nos impérios ocidentais, cada contexto contou com adaptações às suas narrativas a partir de suas intenções políticas e econômicas. A particularidade que interessa a este trabalho corresponde a constatação de que esse tipo de discurso foi construído e estabelecido nos Estados Unidos a partir de meados do século XX. Este contexto estava relacionado com o momento em que o país se firmou como uma potência e consequentemente, deu início às relações de força e poder dos Estados Unidos frente ao Oriente Médio. Ademais, os desdobramentos nas relações com Israel e nos conflitos árabe-israelenses também impactaram as representações orientalistas e a defesa de um ideal liberal ocidental.

Outra obra de Edward Said, pode auxiliar na compreensão de como a imprensa estadunidense representava a questão palestina durante a década de 1990: A Questão da Palestina (2012). Neste livro, Said considerou que a hegemonia dessa imprensa se construiu a partir de um consenso entre a visão liberal ocidental estadunidense e a visão sionista-israelense. Israel é um Estado aliado dos Estados Unidos e, de acordo com o autor, a forma como os sionistas vislumbravam a Palestina se assemelhava ao olhar do imperialista europeu do século XIX. Questão essa que remete, inclusive, a origem do movimento sionista com Theodor Herzl ${ }^{18}$.

Portanto, o conflito entre israelenses e palestinos passou a ser considerado como 'extensão', 'perpetuação' e 'intensificação' do conflito entre Ocidente e Oriente, devido ao alinhamento de Israel com as políticas e ideologias ocidentais e estadunidenses. Assim, os discursos

\footnotetext{
${ }^{16}$ Edward W. Said. Orientalismo: o Oriente como invenção do Ocidente. Tradução Rosaura Eichenberg. (São Paulo: Editora Companhia das Letras, 2016) p. 31.

${ }^{17}$ Idem, p. 123-124; p. 275.

${ }^{18}$ Edward W. Said. A questão da Palestina. Tradução: Sonia Midori. (São Paulo: Editora UNESP, 2012) p. 1015.
} 
estigmatizantes construídos sobre povos árabes e no caso específico, o palestino, buscaram pela personificação de um inimigo a partir de estereótipos que construíram uma visão de alteridade sobre esse 'outro' ${ }^{19}$. Consequentemente, a aliança Estados Unidos e Israel foi colocada a partir de uma autoafirmação como sociedades representantes dos valores democráticos do liberalismo ocidental $^{20}$.

Em vista disso e retomando o conceito gramsciano de hegemonia, Raymond Williams em Cultura e Materialismo (2011), relaciona a hegemonia à ideia de totalidade, de forma que a sua consolidação é possível por meio da busca por uma totalidade, que tem uma intenção por trás, e pode moldar a opinião pública.

A intenção, a noção de intenção, recupera a questão-chave, ou melhor, a ênfase central. Pois embora seja verdade que qualquer sociedade é um todo complexo de tais práticas, também é verdade que toda sociedade tem uma organização e uma estrutura específicas, e que os princípios dessa organização e estrutura podem ser vistos como diretamente relacionados a certas intenções sociais, pelas quais definimos a sociedade, intenções que, em toda a nossa experiência, têm sido regidas por uma classe particu$\operatorname{lar}^{21}$.

Essa intenção, no caso da aliança entre Israel e Estados Unidos, está relacionada com um ethos de missão civilizatória imperialista ocidental, que é colonialista e $\operatorname{racista}^{22}$. A visão construída de um povo inimigo e estigmatizado não é por acaso, mas sim para fins materiais, de dominação territorial, econômica e política. Com isso, a ideia fabricada de um povo palestino terrorista e agressivo, que necessita de uma nação nos moldes ocidentais para controlar e disciplinar, serve como pretexto para a colonização de suas terras ${ }^{23}$.

Uma terceira obra de Edward W. Said nos auxilia a aprofundar os debates sobre o jornalismo estadunidense e suas intenções narrativas. Em Covering Islam (1997), o autor reflete sobre as representações na mídia sobre o "outro" e o que concebia como Islã. As categorias 'árabe', 'muçulmano', 'palestino' eram constantemente tidas como sinônimos pelos veículos de comunicação, sem considerar que na prática, uma classificação não exclui a outra, mas também não são consequências uma da outra, pois refere-se a: uma etnicidade, uma religiosidade e uma identidade nacional, respectivamente. Portanto, a problemática apresentada pelo crítico

\footnotetext{
${ }^{19}$ Edward W. Said. op cit, 2012. p. 22; 33; 43-44; 83; 92-94.

${ }^{20}$ Ressalta-se aqui que essa representação de nações ocidentais democráticas é profundamente ideológica, e essa ideia desconsidera o colonialismo e imperialismo imposto nos países do Sul Global, bem como os problemas de desigualdade social e opressão, intrínsecas ao sistema capitalista.

${ }^{21}$ Raymond Williams. Cultura e materialismo. Tradução: André Glaser. (São Paulo: Editora Unesp, 2011) p. 50.

${ }^{22}$ Edward W Said. op cit., 2012. p. 22.

${ }^{23}$ Acrescenta-se aqui o mito amplamente difundido do Estado de Israel como "única democracia do Oriente Médio". Este seria mais um exemplo da ideia de extensão do conflito entre Ocidente e Oriente, em que o primeiro estaria representado por Israel, uma democracia liberal que atenderia aos moldes ocidentais.
} 
literário palestino é de que o Islã e em decorrência, os árabes e palestinos, eram sistematicamente representados nos veículos de mídia dos Estados Unidos, como um mal a ser combatido da mesma forma que consideravam imprescindível o combate ao comunismo durante a Guerra Fria $^{24}$.

O imaginário em volta da ideia de que palestinos invariavelmente deveriam ser encaixados em rótulos como o de terroristas, tinha como finalidade ofuscar as políticas dos Estados Unidos e de Israel nos territórios palestinos. Segundo Said (1997):

Desafiando a lei internacional e dúzias de resoluções das Nações Unidas, Israel anexou Jerusalém Oriental e as Colinas de Golã, ocupou o sul do Líbano desde 1982, teve uma política de tratar (e caracterizar) os palestinos como sub-humanos - na realidade, uma raça à parte - e exerceu seu poder sobre a política dos Estados Unidos no Oriente Médio, na qual os interesses de quatro milhões de israelenses ofuscaram totalmente os interesses de duzentos milhões de árabes muçulmanos ${ }^{25}$.

Portanto, o consenso, apontado por Said, entre a visão liberal ocidental e a visão sionista-israelense foi motor para a representação sistemática e orientalista do palestino, a partir da percepção de que o confronto entre os dois povos semíticos - árabes e judeus - se insere na conformidade do sionismo com o discurso orientalista ocidental. Desta forma, a legitimação do discurso sionista pelas potências ocidentais, relega ao árabe, o caminho do sujeito a ser apenas representado, a partir de paradigmas estigmatizantes ${ }^{26}$.

Compreender todo esse cenário possibilita apresentar a reportagem em quadrinhos de autoria de Joe Sacco como uma produção cultural estadunidense que quebra com o orientalismo da sociedade em que se insere e, portanto, se coloca em posição contra-hegemônica. Ao elaborar sua narrativa, o jornalista maltês buscou se aproximar ao máximo da história palestina, por meio da coleta de relatos e documentos, leituras sobre a questão e o conhecimento in loco do território e de sua população. Na contramão das grandes mídias estadunidenses as quais estava acostumado a ter contato, buscou sair do discurso amplamente difundido e a partir de um estudo dedicado, possibilitou uma obra que questionasse o establishment e a intelligentsia estadunidense. E esse é o motivo da relevância de Palestina (2011).

\footnotetext{
${ }^{24}$ Edward W. Said. Covering Islam: How the media and the experts determine how we see the rest of the world. (New York: Random House, 1997). Não paginado.

${ }^{25}$ No original: "Defying international law and dozens of United Nations Resolutions, Israel has annexed East Jerusalem and the Golan Heights, has occupied South Lebanon since 1982, has had a policy of treating (and characterizing) Palestinians as sub-human — in effect a race apart — and has wielded its power over United States Middle Eastern policy whereby the interests of four million Israelis totally overshadow the interests of two hundred million Arab Muslims." SAID, Edward W. op cit., 1997. Não paginado (tradução nossa).

${ }^{26}$ Edward W. Said, op cit., 2016. p. 410.
} 


\title{
O conceito de limpeza étnica para a análise dos quadrinhos de Joe Sacco
}

O historiador israelense Ilan Pappé em sua obra A Limpeza étnica da Palestina (2016), faz um balanço sobre as diferentes definições atribuídas ao termo 'limpeza étnica' por meios enciclopédicos e acadêmicos, a fim de traçar uma síntese que defina o conceito. Segundo o autor, o processo estudado consta em:

\begin{abstract}
um esforço para deixar homogêneo um país de etnias mistas, expulsando e transformando em refugiados um determinado grupo de pessoas, enquanto se destroem os lares dos quais elas foram enxotadas. Pode muito bem haver um plano mestre, mas a maioria das tropas engajadas na limpeza étnica não precisa de ordens diretas: sabe de antemão o que é esperado delas. Os massacres acompanham as operações, mas, quando acontecem, não são parte de um plano genocida, mas sim uma tática crucial para acelerar a fuga da população marcada para a expulsão. Mais tarde, os expulsos são apagados da história oficial e popular do país e extirpados da memória coletiva ${ }^{27}$.
\end{abstract}

Segundo Pappé, o processo conhecido pelos palestinos como Al Nakba, a catástrofe palestina iniciada em 1948, configurou os momentos iniciais da limpeza étnica caracterizada pela citação acima. Da mesma forma, esses mesmos acontecimentos possuíram diferentes narrativas consolidadas pelo outro grupo étnico inserido neste contexto. Para o Estado de Israel, o ano de 1948 foi marcado pela Guerra de Independência israelense.

O autor se considera integrante de um grupo de novos historiadores israelenses que propõem uma outra abordagem frente à história oficial israelense. Essa nova abordagem, no caso de Ilan Pappé, configura em uma negação da narrativa construída pelo Estado de Israel sobre a sua fundação, discordando da existência de uma vitoriosa Guerra de Independência. Além disso, o autor reconhece o discurso da Al Nakba palestina como um dos momentos iniciais desse processo que estuda, mas propõe ir além, pensando em uma continuidade das ações praticadas pelo Estado de Israel desde o ano de 1948. Portanto, A limpeza étnica da Palestina (2016),

Em um primeiro momento, é uma negação da narrativa oficial israelense que buscou uma narrativa heróica, de orgulho nacional, para o que posteriormente foi chamado de a Primeira Guerra Árabe-Israelense e sua decorrente ocupação territorial da Palestina. No entanto, o autor, apesar de não negar os conflitos ocorridos no ano de 1948 com a invasão de aldeias e expulsão dos nativos - que configura a Al Nakba -, procurou construir uma narrativa que compreendesse esses eventos como iniciais de um processo mais longo, ao qual abarcou outras temporalidades e esferas da vivência entre os dois povos: a limpeza étnica ${ }^{28}$.

\footnotetext{
${ }^{27}$ Ilan Pappé. A Limpeza Étnica da Palestina. Tradução: Luiz Gustavo Soares. (São Paulo: Editora Sundermann, 2016) p. 23.

${ }^{28}$ Débora Pinese Frias. DESENHANDO A OCUPAÇÃO ISRAELENSE: traços de denúncia de uma limpeza étnica em Palestina, de Joe Sacco (1948-1992). Trabalho de Conclusão de Curso (graduação em História) - Universidade Federal de São Paulo, Escola de Filosofia, Letras e Ciências Humanas, 2021.p. 36.
} 
De forma a inserirmos o processo em termos materiais, conforme Pappé, o início do processo de limpeza étnica se deu através das invasões militares às aldeias palestinas, pelas organizações paramilitares, como Irgun e a Gangue Stern. Essas invasões iniciaram-se durante o ano de 1948, a partir dos planos de invasão estudados pelo historiador israelense: Plano A, Plano B, Plano C (Gimel), Plano D (Dalet) ${ }^{29}$. No entanto, dois outros fatores também contribuíram a este cenário, que foram: a intensa imigração de judeus provindos de países europeus e as decorrentes compras de terras palestinas através do Fundo Nacional Judeu (FNJ), que buscava uma "redenção da terra" e uma colonização com aspirações sionistas.

O momento inicial do processo de limpeza étnica é representado por Joe Sacco através do relato de um senhor palestino, que no ano de 1948 morava junto à sua mulher e pai em um vilarejo que foi atacado pelas forças sionistas (Figura 1). Segundo ele, seu pai foi preso junto a outros que ficaram no vilarejo e não conseguiram fugir, enquanto ele e sua esposa, que estava grávida, andaram por quatro dias a pé com risco de serem bombardeados pelos israelenses e sem ajuda do exército egípcio que ali estava. Posteriormente, durante a entrevista, o senhor afirmou que onde se localizava a aldeia em que morou, em sua atualidade já não era mais possível de identificar qualquer indício de sua existência em algum momento passado. Essa passagem, além de mostrar o apagamento material de qualquer resquício de uma prévia ocupação, que não a isralense, evidencia a negação aos palestinos do direito de retorno permanente às terras das quais foram obrigados a fugir no passado ${ }^{30}$.

\footnotetext{
${ }^{29}$ Ilan Pappé. A Limpeza Étnica da Palestina. Tradução: Luiz Gustavo Soares. (São Paulo: Editora Sundermann, 2016) p. 14.

${ }^{30} \mathrm{O}$ 'direito de retorno' à Israel é assegurado a todo e qualquer judeu, independente de sua nacionalidade, devido a pretensão sionista de construção de um Estado étnica e exclusivamente judaico, enquanto para os palestinos, esse direito é negado desde o início da ocupação sionista.
} 


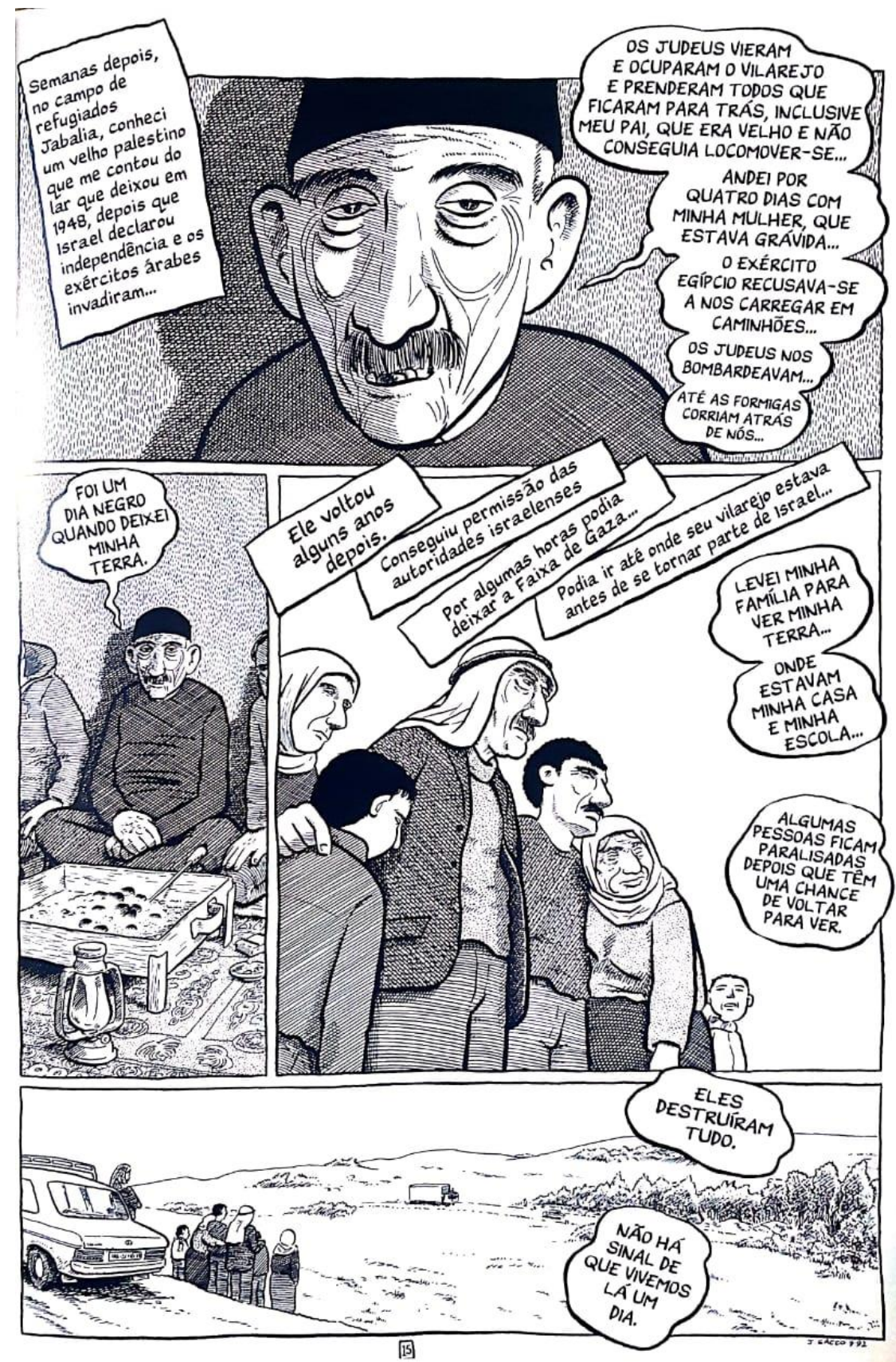

Figura 1 - Relato de senhor palestino expulso de suas terras no ano de 1948. In: SACCO, Joe. op cit. 2011, p. 15.

Posterior aos eventos de 1948, com a invasão, expulsão e desapropriação de terras palestinas, em concomitância à consolidação de um Estado étnico-nacional israelense, houve a continuidade das ações políticas e militares de expulsão, segregação e apagamento da população palestina de seus próprios territórios, como forma cotidiana e sistemática de opressão. Tendo isso em vista, objetiva-se aqui apresentar como a obra de Joe Sacco pode nos proporcionar informações para compreender o processo de limpeza étnica através da linguagem particular da reportagem em quadrinhos. 
Isso porque o processo de limpeza étnica buscou afetar diversos aspectos da vida palestina, segundo Pappé: homogeneizar a população étnica do local, através da expulsão e destruição dos lares daqueles que se refugiam; massacres e violências aplicados como forma de expulsão e o posterior apagamento da história daqueles que foram expulsos. Uma das formas de violência aplicada ao povo palestino se relaciona ao ataque à manutenção de suas vidas, a partir da destruição de oliveiras palestinas. Esse tipo de cultivo é responsável por grande parte do sustento de muitas famílias palestinas e, portanto, o corte dessas árvores pelo poder ocupante é um modo de agressão à sua sobrevivência, que é aplicado de forma sistemática pelo Estado de Israel $^{31}$.

Em notícia publicada pela revista Veja, em 14 de novembro de 2011, o Ministério da Economia palestino alegou que “desde que começou a ocupação em 1967, Israel destruiu mais de 800 mil oliveiras, o que implica uma perda anual de US\$ 55 milhões.” ${ }^{\text {¡2 }}$. Essa denúncia é significativa por apresentar-nos como os meios de subsistência dos palestinos são frequentemente atacados sob ocupação, principalmente após os eventos de 1967, no que ficou conhecido como Terceira Guerra Árabe-Israelense, em que Israel anexou os territórios da Faixa de Gaza, Cisjordânia e Colinas de Golã, ignorando as divisões territoriais estabelecidas pela ONU e intensificando seu poder colonial.

O assunto das oliveiras é abordado por Joe Sacco em Palestina (2011), durante o subcapítulo Oceano. “Oceano”, pois a família entrevistada pelo jornalista, que aparece representada durante essa passagem é apenas "uma gota no oceano" de famílias palestinas que tiveram seus cultivos destruídos. A metáfora é utilizada como forma de afirmar que essa é uma prática sistemática da ocupação, de modo a inserir o evento em um contexto mais amplo. De acordo com o autor: "Os israelenses cortaram 120 mil outras árvores nos primeiros quatro anos da

\footnotetext{
31 Algumas denúncias em notícias e relatórios da Coordenação de Assuntos Humanitários da Organização das Nações Unidas (ONU), ver: B’TSELEM. Israel demolishes agricultural structure and dirt road and cuts down approx. 100 olive trees in northern Jordan Valley.16 de ago de 2021. Disponível em: <https://www.btselem.org/facing_expulsion_blog?nid=213166>. 26 de out de 2021.

PRESSE, F. Colonos israelenses arrancam mais de 100 oliveiras de palestinos na Cisjordânia. Disponível em: <http://g1.globo.com/economia/noticia/2012/10/colonos-israelenses-arrancam-mais-de-100-oliveiras-de-palestinos-na-cisjordania.html>. Acesso em: 09 fev. 2021.

Protection of Civilians Report | 19 January - 1 February 2021. Disponível em: <https://www.ochaopt.org/poc/19january-1-february-2021>. Acesso em: 09 fev. 2021.

The olive harvest and settler violence: the case of Al Mughayyir village | October 2013. Disponível em: <https://www.ochaopt.org/content/olive-harvest-and-settler-violence-case-al-mughayyir-village-october-2013>. Acesso em: 09 fev. 2021.
}

${ }^{32}$ A. Cádernes. Israel transforma colheita da azeitona palestina em sofrimento.

Disponível em: <https://veja.abril.com.br/mundo/israel-transforma-colheita-da- azeitona-palestina-em-sofrimento/>. Acesso em: 09 fev. 2021. 
Intifada.... por "razões de segurança", como nesses casos... ou para construir a rede de estradas que liga os assentamentos judeus a Israel...."

O primeiro relato da família entrevistada, foi de uma mulher que relatou o evento duas semanas após o seu acontecimento. Conforme seu testemunho, as forças israelenses impuseram um toque de recolher durante a madrugada, após uma confusão à noite entre dois palestinos e um colono judeu. À tarde do dia seguinte, foram cortadas oliveiras dos seus vizinhos e árvores da rua. No outro dia, os soldados voltaram e cortaram as oliveiras da entrevistada. Ao todo, segundo o relato, setenta oliveiras, de treze famílias foram cortadas nesse vilarejo ${ }^{34}$.

O segundo relato dessa família foi dado pelo pai da mulher, sobre um acontecimento de dois anos antes. De acordo com o senhor palestino, soldados israelenses mandaram que ele instalasse por sua conta, uma cerca em volta de seu terreno, devido a um ataque de pedras ou coquetel molotov, que teriam sido atiradas de seu campo. Essa exigência, se não fosse cumprida, acarretaria na punição em que o senhor teria suas oliveiras cortadas. Sem condições de cumprir com a imposição, o entrevistado relatou que não conseguiu instalar a cerca e foi obrigado a derrubar suas próprias árvores e acabar ele próprio com os seus meios de subsistência, como forma de castigo ${ }^{35}$, conforme a Figura 2. Ademais, as oliveiras palestinas por ser uma árvore milenar, podem ser consideradas símbolos da resistência palestina às adversidades, e o ataque a elas, pode configurar também um ataque à resistência desse povo em níveis simbólicos.

\footnotetext{
${ }^{33}$ Joe Sacco. op cit. 2011, p. 62.

${ }^{34}$ Idem, p. 60.

${ }^{35}$ Joe Sacco, op cit., 2011, p. 61-62.
} 


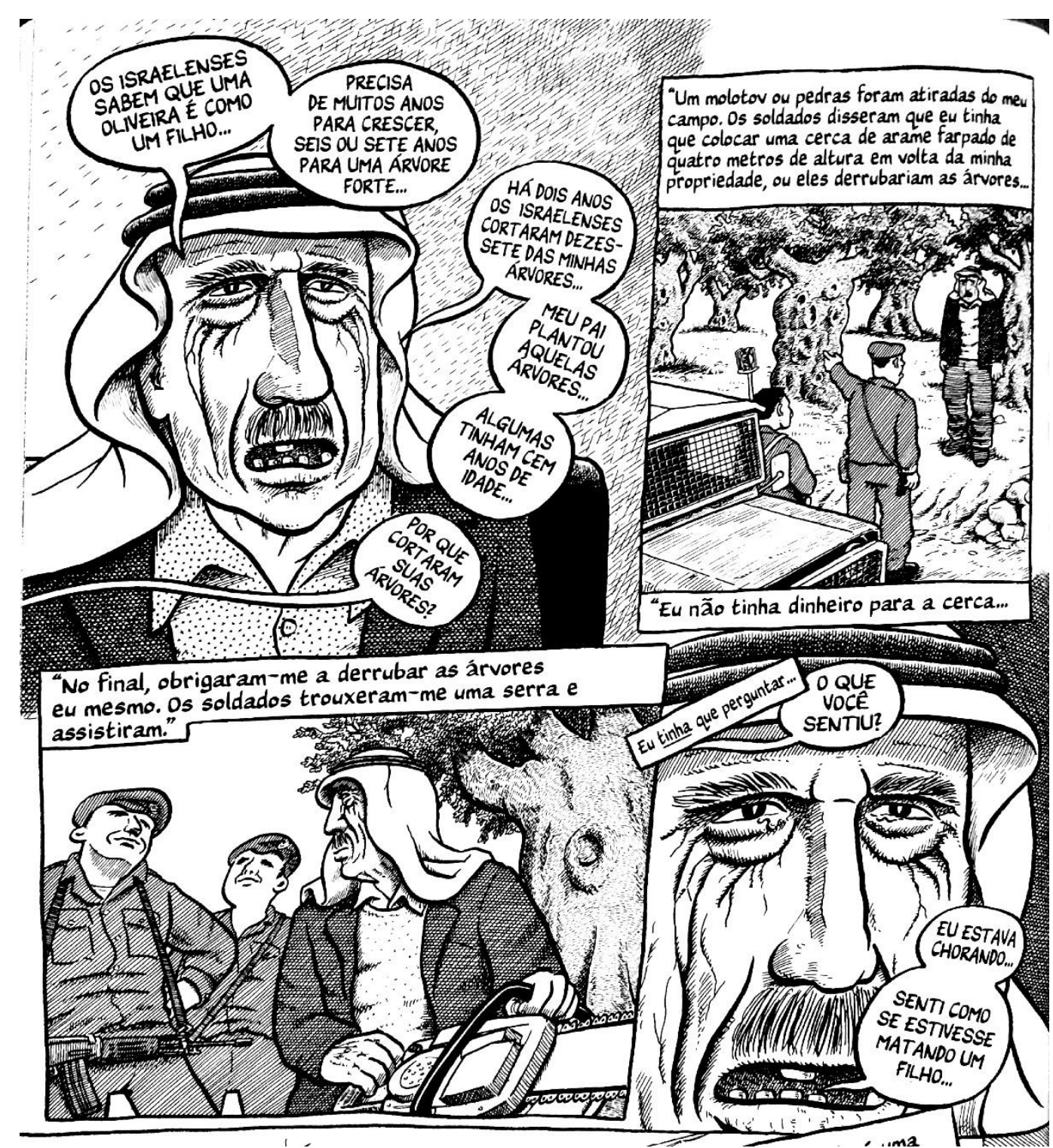

Figura 2 - Senhor palestinó relembra de quando foi obrigado a destruir suas próprias oliveiras. In: SACCO, Joe. op cit., 2011. p. 62.

Outro momento em que podemos reconhecer uma observação de Joe Sacco sobre os locais visitados que dialoga com o conceito de limpeza étnica aqui apresentado, acontece ao final da sua narrativa. Após toda a sua estadia e entrevistas feitas na Palestina, Joe Sacco visita brevemente a cidade de Tel Aviv junto a duas personagens israelenses que o jornalista conheceu e entrevistou naquele momento. Nessa passagem, Sacco identifica semelhanças com cidades dos Estados Unidos e Europa na paisagem israelense, colocando que a cidade parece "familiar aos meus ouvidos e olhos ocidentais" ${ }^{36}$, conforme consta na Figura 3. A naturalização de uma paisagem dita ocidental em territórios do Oriente Médio é significativa quando refletimos sobre

\footnotetext{
${ }^{36}$ Joe Sacco. op cit, 2011 . P. 261.
} 
os processos de ocupação israelense e de limpeza étnica, iniciados em grande parte por uma imigração europeia.

Além disso, termina essa passagem apontando que Naomi e Paula possuem um modo de vida e preocupações cotidianas que lhe parecem muito familiares. Isso porque o cotidiano de ocupação não é percebido e sentido da mesma forma em cidades israelenses e palestinas. Enquanto palestinos são expulsos de suas terras, têm seus direitos cerceados, suas condições de vida atacadas, são presos e torturados, em territórios como Tel Aviv a militarização do cotidiano não se faz perceptível, parecendo assim, como qualquer outra cidade aos moldes ocidentais.

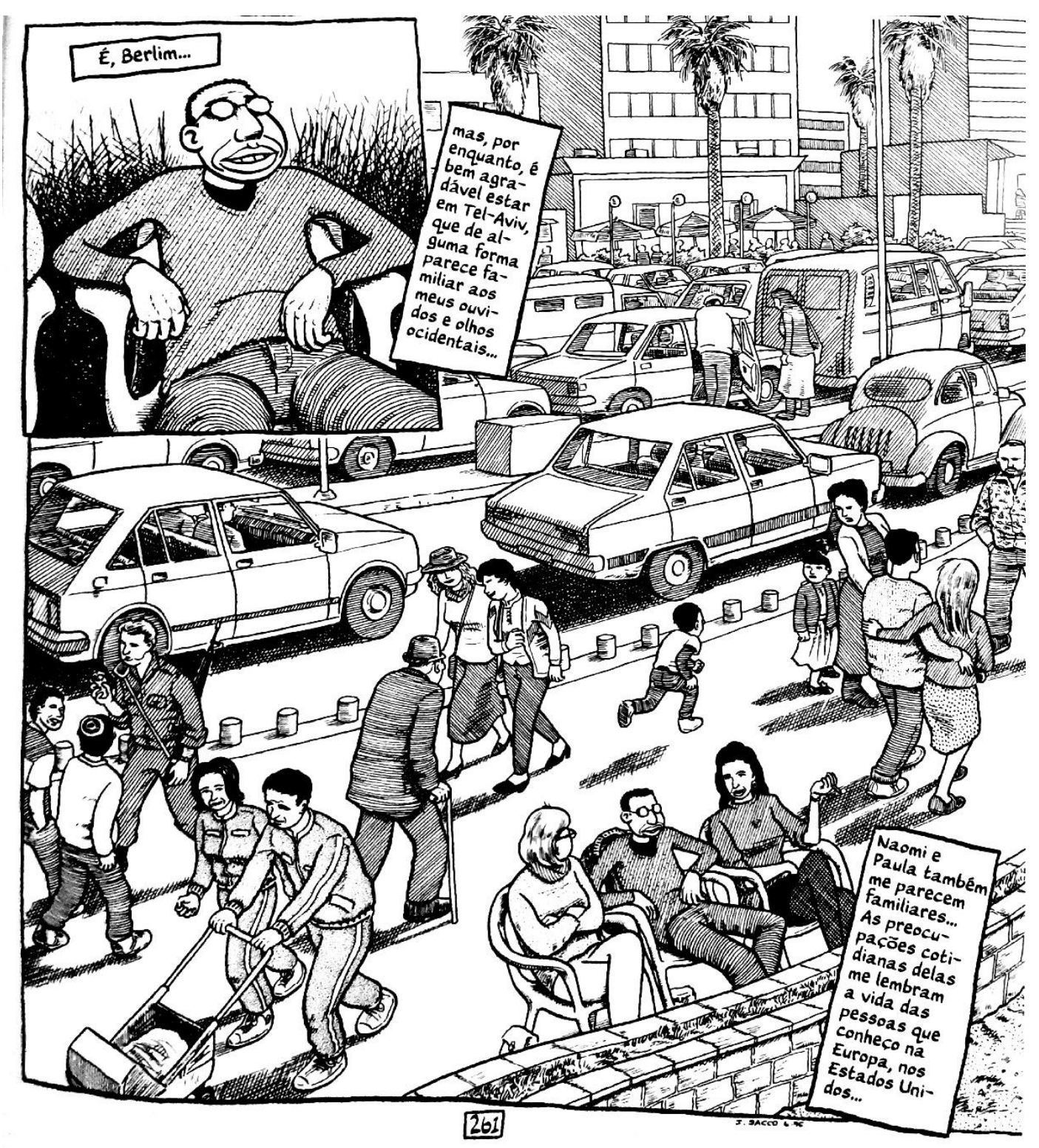

Figura 3 - Visita de Joe Sacco a Tel Aviv. In: SACCO, Joe, op cit., 2011, p. 261. 
Ressalta-se aqui a necessidade de uma importante problematização ao abordar essa passagem: devemos evitar essencializar a questão. A ideia trazida por Joe Sacco quando apresenta uma paisagem e problemas cotidianos que se assemelham aos ocidentais é relevante para compreendermos a diferença da realidade imposta nas sociedades que sofrem a ocupação e na que impõe a ocupação. Não estamos falando de um embate de forças políticas e militares equânimes, mas sim de uma ocupação colonial e, portanto, a opressão cotidiana vivenciada pelos palestinos, de fato se contrapõe às aparências de Tel Aviv como uma cidade que atende aos moldes ocidentais. No entanto, é fundamental ter em nosso horizonte que não devemos reproduzir a ideia de relegar aos palestinos apenas o papel de vítimas passivas. A resistência palestina perdura desde o ano de 1948 e trabalhos como Palestina são necessários para a aproximação com a causa e a decorrente solidariedade.

\section{Conclusão}

A reportagem em quadrinhos Palestina proporciona uma diversidade de assuntos dos quais fogem às abordagens tradicionais feitas pelos grandes meios de comunicação e pela opinião pública. O autor Joe Sacco, por meio de métodos apreendidos durante sua formação em jornalismo, conseguiu se aproximar de informações que seriam conseguidas em reportagens convencionais, entrevistas etc. No entanto, a sua forma de apresentar esses relatos foi aplicada em um gênero narrativo que proporciona uma maior abertura quanto às histórias e temáticas retratadas.

Isso posto, compreende-se que a obra em questão deve ser lida como uma reportagem em quadrinhos, que busca na materialidade e nos relatos dos entrevistados, suas fontes basilares para a construção narrativa. Ademais, os quadrinhos proporcionam uma abertura criativa ao autor, que pode desembocar em duas consequências: uma maior subjetividade textual e uma maior liberdade nas temáticas a serem abordadas. Se por um lado devemos ter parcimônia ao ler a história e entendê-la como uma representação do seu próprio autor e do resultado de relatos pessoais dos entrevistados, por outro, valorizemos a possibilidade de introdução de temas que até então eram mal representados, ou não representados.

Adicionemos à questão da não objetividade narrativa presente na reportagem em quadrinhos, uma constatação importante: o jornalismo convencional padece de questões semelhantes. A suposta objetividade perseguida e defendida por diversos meios de comunicação, seus representantes e suas empresas, resulta mais em retórica do que prática. Ao adotar uma linguagem 
não habitual para Palestina, junto a métodos do jornalismo de busca e coleta de informações, Joe Sacco não só deixa de lado a ideia de neutralidade, mas vai além ao conseguir conciliar em seus traços informações sobre o contexto representado e as suas opiniões.

Em vista disso, analisar a reportagem em quadrinhos como um produto cultural de seu próprio tempo e profundamente relacionado com o contexto de sua produção, é essencial para uma interpretação adequada. Primeiro, porque os seus antecessores e contemporâneos traçaram caminhos no mundo dos quadrinhos que expandiram as possibilidades do campo que provavelmente impactaram na produção de Sacco, bem como a formação universitária do autor forneceu a ele cabedal para tal feito. Em segundo, porque as poucas ou más interpretações identificadas pelo autor no cenário jornalístico estadunidense, despertaram a necessidade de uma obra que estivesse na contramão. Em terceiro, porque as possibilidades que Joe Sacco teve de buscar informações in loco e por meio de autores que debatiam a causa palestina, fizeram com que ele se aproximasse da questão, de forma a entender mais profundamente e se posicionar publicamente.

Em suma, Palestina é uma obra que tem um potencial de conscientização para a causa palestina, justamente porque Sacco se coloca como uma personagem durante a narrativa, de forma a questionar as próprias visões pré-concebidas que tinha antes de se deparar com o contexto palestino. Da mesma forma, pela liberdade temática concedida através da linguagem escolhida, a história em quadrinhos apresentou uma quebra com uma narrativa consolidada, que foi capaz de apresentar uma visão contra-hegemônica e anti-orientalista frente aos países que se inserem na lógica ocidental, principalmente os Estados Unidos.

\section{Referências Bibliográficas}

B'tselem. Israel demolishes agricultural structure and dirt road and cuts down approx. 100 olive trees in northern Jordan Valley.16 de ago de 2021. Disponível em: <https://www.btselem.org/facing_expulsion_blog?nid=213166>. 26 de out de 2021.

Cárdenes, A. Israel transforma colheita da azeitona palestina em sofrimento. Disponível em: $<$ https://veja.abril.com.br/mundo/israel-transforma-colheita-da-azeitona-palestina-em-sofrimento/>. Acesso em: 09 fev. 2021.

Cevasco, Maria Elisa. Dez lições sobre estudos culturais. 1.ed. São Paulo: Boitempo, 2003.

Dutra, Antônio Aristides Corrêa. Quadrinhos de não-ficção. In: INTERCOM- Sociedade Brasileira de Estudos Interdisciplinares da Comunicação XXVI Congresso Brasileiro de Ciências da Comunicação, 2003, Belo Horizonte (MG). 
Frias, Débora Pinese. Desenhando a ocupação israelense: traços de denúncia de uma limpeza étnica em Palestina, de Joe Sacco (1948-1992). Trabalho de Conclusão de Curso (graduação em História) - Universidade Federal de São Paulo, Escola de Filosofia, Letras e Ciências Humanas, 2021.

Gramsci, Antonio. Cadernos do cárcere: volume 3 : Maquiavel, notas sobre o estado e a política. 3. ed. Rio de Janeiro: Civilização Brasileira, 2007.

Pappé, Ilan. A Limpeza Étnica da Palestina. Tradução: Luiz Gustavo Soares. São Paulo: Editora Sundermann, 2016.

Presse, F. Colonos israelenses arrancam mais de 100 oliveiras de palestinos na Cisjordânia. Disponível em: <http://g1.globo.com/economia/noticia/2012/10/colonos-israelenses-arrancam-mais-de-100-oliveiras-de-palestinos-na-cisjordania.html>. Acesso em: 09 fev. 2021.

Protection of Civilians Report | 19 January - 1 February 2021. Disponível em: < https://www.ochaopt.org/poc/19-january-1-february-2021>. Acesso em: 09 fev. 2021.

Rangel, P. "Desenhando o conflito Israel-Palestina: narrativas e representações em HQs." $M a$ lala, n. 3, p. 76-106, 2014.

Sacco, Joe. Palestina. Tradução de Cris Siqueira. Edição Especial. São Paulo: Conrad Editora do Brasil, 2011.

Said, Edward W. A questão da Palestina. Tradução: Sonia Midori. São Paulo: Editora UNESP, 2012.

Said, Edward W. Orientalismo: o Oriente como invenção do Ocidente. Tradução Rosaura Eichenberg. São Paulo: Editora Companhia das Letras, 2007.

Said, Edward W. Covering Islam: How the media and the experts determine how we see the rest of the world. New York: Random House, 1997.

The olive harvest and settler violence: the case of Al Mughayyir village | October 2013. Disponível em: <https://www.ochaopt.org/content/olive-harvest-and-settler-violence-case-almughayyir-village-october-2013>. Acesso em: 09 fev. 2021.

Williams, Raymond. Cultura e materialismo. Tradução: André Glaser. São Paulo: Editora Unesp, 2011. 